\title{
形象比拟法在大学植物学 “中轴胎座”教学中的应用
}

\author{
张仁波 ${ }^{12}$ 窦全丽 ${ }^{12}$
}

1 遵义师范学院 生物与农业科技学院 2 赤水河流域环境保护与山地农业发展协同创新中心

DOI:10.32629/er.v3i2.2487

[摘 要] 在大学植物学教学中使用奔驰和宝马车标来形象比拟 “中轴胎座”, 在知识目标方面可以加深学生对该胎座类型的理解,在能力目标 方面可以提升学生抽象思维的能力,在情感目标方面可以引导学生建立正确的价值观并抵制拜金主义的影响。

[关键词] 形象比拟法; 植物学教学; 中轴胎座

The application of image analogy in the teaching of "axial placenta" in university botany Zhang Ren-Bo Dou Quan-Li

Department of Biology, Zunyi Normal College

Collaborative Innovation Center of Environmental Protection and Mountain Agricultural Development in Chishui River Basin

[Abstract] Using Benz and BMW logo to carry out image analogy in the teaching of "axial placenta” , students can deepen the understanding of this kind of placenta in terms of knowledge objectives. It also can promote students' ability of abstract thinking. In terms of emotional goal, students can be guided to establish correct value sense and resist the influence of money worship.

[Key words] image analogy; botany teaching; axial placenta

形象比拟法是指教师在教学中借用学生已感知的知识来映射新知识, 使新知识更容易被理解的教学方法 ${ }^{[1]}$ 。该方法可以把抽象的概念形象化, 帮助学生深入理解概念的含义 ${ }^{[1]}$ 。

中轴胎座是指多心皮多室的复子房, 肧珠着生在各室的内隅并沿中轴 周围排列的一种胎座类型 ${ }^{[2]}$ 。具有中轴胎座的植物类群很多, 如百合目等 单子叶植物, 以及山茶目、锦葵目、桃金娘目、杜鹃花目和柿树目等双子 叶植物 ${ }^{[3]}$ 。

3 心皮的中轴胎座, 从横切面上看具有 3 室、3个隔膜和若干胚珠 (图 1-a), 如果将胚珠去掉, 子房壁和 3 个隔膜 (图1-b和1-c) 与奔驰车的车标 (基本组成为一个三角星徽外面包围着一个圆环 ${ }^{[4]}$ ) 相似。现在, 部分大学 生已经开始申领机动车驾驶证, 且社会车辆保有量持续增加, 不少学生对 各种车标较感兴趣并有一定的认识。奔驰车标对于大多数学生来说是已感 知的知识, 可以用来映射中轴胎座这个新知识。
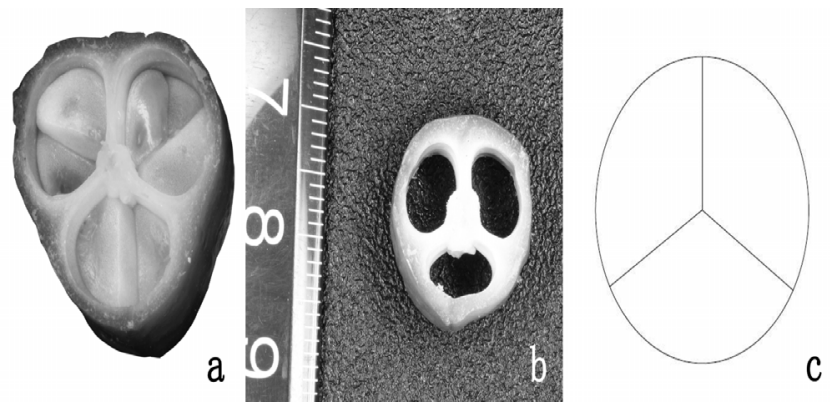

图1 3心皮中轴胎座横切图及示意图

注: $a$ 为蝴蝶花果实横切, 示中轴胎座及种子; $b$ 为 $a$ 去掉种子的横切图, 示子房壁和隔膜; $c$ 为 $b$ 的简笔画示意图。

从教学实践来看, 学生普遍对将没有胚珠的 3 心皮的中轴胎座比拟成 奔驰车标很感兴趣, 这能吸引学生的注意力, 并起到寓教于乐的的作用。对 于该知识点, 可以在PPT上展示 3 心皮中轴胎座的横切图, 并在黑板上辅以 简笔画 (图1-c), 可以加深学生对该胎座类型的理解。

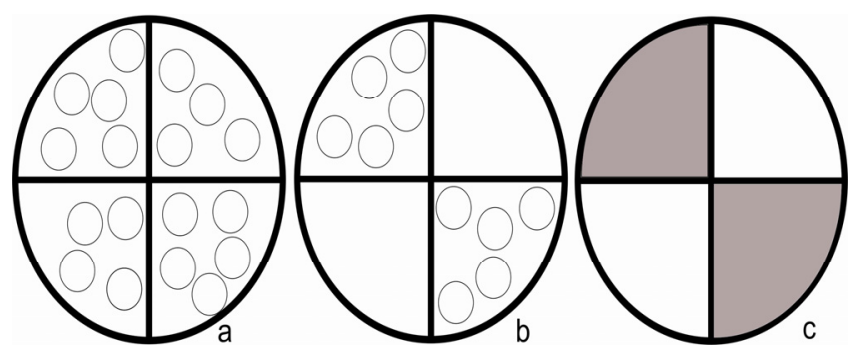

图24心皮中轴胎座横切示意图

注: $\mathrm{a}$ 表示 4 室均具有肧珠; $\mathrm{b}$ 表示去掉第 1,3 象限的胚珠; $\mathrm{c}$ 为在黑板 上用白色粉笔涂抹第 1,3 象限的效果图。

类似地, 4 心皮的中轴胎座, 从横切面上看具有 4 室、 4 个隔膜和若 干胚珠 (图2-a), 如果将第 1,3 象限 (或 2, 4象限) 的胚珠去掉 (图2-b), 第 1,3 象限与第 2,4 象限颜色明显不同的中轴胎座横切面与宝马车的车标 相似。宝马车标为蓝色和白色相间的圆形图案, 蓝色代表天空而白色代 表螺旋浆 ${ }^{[5]}$ 。在该知识点的教学过程中, 可以在PPT上展示4心皮中轴胎座 横切面的照片, 并在黑板上辅以简笔画 (用粉笔画一个圆圈, 在圆圈内画一 个十字, 然后在第 1,3 象限用白色粉笔涂抹表示无胚珠 (也可表示具有胚 珠), 效果即接近图 2-c)。这样, 可以加深学生对 4 心皮中轴胎座的理解, 还可以提升学生抽象思维的能力。

近年来, 校园贷和拜金主义在大学内不断蔓延。校园贷虽然门槛低并 且操作便利, 但大学生往往忽视其背后的高风险 ${ }^{[6]}$ 。此外, “宝马女” 事件 被当成了拜金主义的典型案例之一 ${ }^{[7]}$ 。目前, 不少大学教师也开始注重在 教学中引导学生抵制拜金主义的影响 $[8,9]$ 。在大学植物学 “中轴胎座” 这 部分内容的教学过程中, 将奔驰和宝马车标都比拟为同一知识点 (3心皮 或4心皮的中轴胎座), 再稍作延伸, 车辆只是代步工具而已, 有条件可以 用配置好一点的, 没条件用配置弱一点的也同样起到代步作用。这样可 以给学生一种平等的心理暗示, 在一定程度上可以起到削弱学生攀比心 理的作用。 


\title{
我国高校教学管理的现状和强化方法
}

\author{
王昱洁 \\ 北京农业职业学院 \\ DOI:10.32629/er.v3i2.2499
}

[摘 要] 高校教学管理水平对于高校的发展进步有着直接的影响,因此,近几年来,也逐渐受到了我国高校和相关教育部门的重视。基于此,下文 就高校教学管理的主要内容、高校教学管理的现状和强化方法方面进行了简单讨论。

[关键词] 高校; 教学管理; 内容; 现状; 强化方法

\section{引言}

新时期下, 随着我国教育改革进程的推进, 其对于我国高校的教育管 理工作也提出了更加深层次的要求, 为此, 高校需要加强对教学管理工作 的重视, 明确教学管理的主要内容, 从而立足于当前我国高校教学管理工 作的现状, 研究相关的强化措施, 以此来提高我国的教育教学水平, 最终促 进我国高等教育的整体发展。

\section{1 我国高校教学管理的主要内容}

1. 1在教学管理制度方面的内容

教学管理制度是高校教学管理工作的基础, 因此, 也是高校教学管理 工作的主要内容, 其贯穿于高校教学管理工作的整个过程中, 对高校的一 系列教学管理行为都有着监控和调整的作用。

我国高校的教学管理制度在实际制定的过程中主要是根据高校的定 位和人才培养目标来制定的, 在实际的制定过程中, 需要高校的教学事务 部门来制定具体管理性质的文件, 然后再下达给各个二级学院间执行。通 常情况下, 高校的教学管理制度都包含着教学研究制度、教学考务制度、 教学质量监控制度以及工作安排制度等等, 为高校的教学管理工作提供了 科学的指导, 对于学生的专业知识和学业要求上也有较为明确的要求, 是 我国高校教学管理工作的前提保障。

\section{2在教学运行方面的内容}

高校的教学运行主要指的是在宏观的教学目标的指导下, 对高校的 教学活动进行科学的计划、实施和管控。按照高校的教学活动的实施程 序来分析, 教学运行活动主要可以分为教学基本建设管理, 例如, 高校的 学科建设、专业建设、实践教学程序建设等等、日常教学管理, 例如高 校的课程教学大纲以及教学实践等、教学质量管理, 主要包含高校教学 全过程的质量监控、教学质量检查和教学评价等。在这三个教学管理工 作中, 教学基本建设管理主要指的是高校在教学活动正式开展之前的教 学规划工作, 具有一定的预测性和不稳定性, 在具体实施的过程中会根

\section{[参考文献]}

[1]丁雷.信息技术教学中形象比拟法的运用 [J].中国电化教 育,2004(06):59-60.

[2]陆时万,徐祥生,沈敏健.植物学(上册)[M].北京:高等教育出版社,2011.

[3] 吴国芳, 冯志坚,马炜梁,等.植物学(下册) [M].北京:高等教育出版 社,2011.

[4]蒋成富.车标漫谈——戴姆勒・奔驰公司[J].汽车运用, 1997(6):22-23.

[5]恺文.宝马传奇[J].沪港经济,2014(09):18-21.

[6]彭照华.大学生使用校园贷的心理原因及对策[J].科教文汇（上旬 刊),2019(10):159-160+163.

[7]百度百科.宝马女[Z].https://baike.baidu.com/item/,2019-11-18.
据高校的日常教学管理和教学质量管理工作的进行而发生变化, 因此, 也可以说, 高校的日常教学管理和教学质量管理工作是高校教学运行的 重点内容。

\section{3 在教学管理环境方面的内容}

高校的教学管理环境对于其教学管理制度有着一定的支撑作用, 具体 包含着高校的教学管理理念、教学管理文化和管理者与被管理者之间的人 际管理。高校的教学管理环境在实际构建的过程中需要教学管理者和被管 理者之间的相互作用, 以此来完善高校的教学管理环境。另外, 高校的教学 管理环境在一定意义上也体现着高校的教学氛围和教学文化。

1. 4 在管理队伍方面的问题

高校教学管理队伍的建设对于其教学管理制度的实施效果有效直接 的影响, 因此, 也是高校教学管理工作的重要内容。高校教学管理队伍管理 也指的是高校的人才管理, 对于实现高校的各项教学管理目标有着至关重 要的作用。目前, 我国高校对于教学管理队伍的要求还较低, 使其具备基本 的管理技能即可。但是, 在现代化的教学背景下, 高校要想提高教学管理工 作的水平, 还需要提高管理队伍的培养标准, 提高管理人才的专业化, 进而 为高校的教学管理工作提供人才保障。

\section{2 我国高校教学管理的现状}

2.1 教学管理观念较为落后

现阶段, 我国高校在教学管理工作上,存在的最主要的问题就是教学 管理观念还较为落后。具体表现为: 第一, 部分高校的教学管理人员单纯 的将教学管理工作看做是一项事务性的工作, 因此, 在实际的教学管理工 作中, 更加重视对物的管理, 通常情况下, 采取的都是行政命令性的管理方 法进行管理, 使得管理工作不够人性化; 第二, 由于高校的教学管理工作具 有一定的复杂性, 而管理人员的管理观念还没有做到与时俱进, 采取的管 理方法较为传统, 在一些小的教学管理方面难以控制, 进而使得教学管理 工作的水平还有待提高 ${ }^{[1]}$ 。
[8]房廷宏,李精华.教学中引导学生抵制拜金主义影响的思考[J]. 黑龙 江高教研究,2003(03):144-145.

[9]王欢,赵红.利用信息化教学手段揭开“校园贷”的真实面目一一复 利终值和现值的计算[J].才智,2019(16):43.

\section{作者简介：}

张仁波(1977--), 男, 汉族, 贵州桐梓人,博士,教授,遵义师范学院, 主要研究植物分类学和植物生态学

\section{资助项目:}

遵义师范学院2019年度教学内容与棵程体系改革建设项目 (JGKT2019007); 贵州高等学校创新能力提升计划(黔教合协同创新字 [2013]11)；遵义师范学院博士基金项目(遵师BS[2018]17号) 